\title{
Measuring the Impact of a Conditional Cash Transfer Program on Consumption Behavior with Propensity Scoring
}

\author{
Wagner A. Kamakura • Jose Afonso Mazzon
}

Published online: 24 February 2015

(C) Springer Science+Business Media New York 2015

\begin{abstract}
Conditional cash transfer (CCT) programs are quickly replacing old welfare programs because they help the poorest members of society both on the short and long terms. On the short term, the extra discretionary income provided by these programs help participant families meet their pressing basic needs. On the long term, these cash transfers are conditional on participants engaging in health and educationrelated activities that directly benefit their children, as an attempt to extract the new generation from the vicious circle of poverty. The impact of CCT programs on their main goals (health, education, and nutrition) has already been widely tested and documented. The main purpose of our current study is to assess the impact of a fully implemented program (Bolsa Familia in Brazil) on consumption behavior. This is important for several reasons. First, CCT programs represent a substantial boost in participants' discretionary income, all funneled into consumption, resulting into a substantial additional demand for certain product categories. Second, critics of CCT programs claim that most of this discretionary income is squandered in superfluous consumption, pushing these poor households into new unsustainable lifestyle. Third, most tests of the impact of CCT programs are based on controlled experiments conducted either before or at the beginning of the program's full implementation. In contrast, our assessment is done after Bolsa Familia has been fully implemented, which required us to design a natural experiment combining propensity scoring with econometric modeling. Based on this natural experiment, we are able to quantify the effect of Bolsa Familia on its participants and also the incremental demand for various product categories generated by this CCT program. Contrary
\end{abstract}

W. A. Kamakura ( $\square)$

Rice University, Houston, TX, USA

e-mail:kamakura@rice.edu

\section{J. A. Mazzon}

Universidade de São Paulo, São Paulo, SP, Brazil to what detractors of the program claim, we find that most of the extra cash is devoted to essential goods (food, clothing, etc.) rather than superfluous consumption.

Keywords Conditional cash transfers - Welfare programs . Propensity scoring $\cdot$ Natural experiment $\cdot$ Consumption · Emerging economies

\section{Introduction}

The main purpose of this study is to measure how a nationwide conditional cash transfer (CCT) program affected consumption priorities among participating families. Conditional cash transfer programs are characterized by periodic payments by the government to extremely poor families that meet certain qualifications such as per capita income below the subsistence level and presence of children or pregnant women in the household [7, 34]. However, in order to receive each of the periodic cash transfers, these families must demonstrate compliance to certain requirements or conditions, such as (a) school attendance by their children and adolescents, (b) immunization and anthropometric tracking of children in the family, (c) pre-natal care of pregnant women, (d) training on nutrition and breast feeding, and/or (e) adult participation in literacy programs $[25,37]$.

As we review later, the impact of CCT programs on the targeted behaviors and recipients' welfare has been already extensively investigated $[2,3,34,36]$. Our study differs from previous ones in two important aspects. First, we focus on how the largest CCT program in the world (Bolsa Familia) affected consumption behavior among the poor families participating in the program. In contrast, previous studies have focused mainly on the impact of these CCT programs on compliance to the conditions imposed by the programs and 
on general welfare. Second, rather than relying on controlled experiments on relatively small samples $[16,27,36]$ conducted before the program was fully implemented, we rely on a large representative national sample of households, to assess the impact of the program after the program has been fully implemented at the national level. Because we assess the impact of the program after full implementation, rather than predicting its potential impact within a controlled experiment, we cannot randomly assign subjects to a control or treatment group in the typical before-after controlled experiment. Instead, we rely on actual implementation data to create a natural experiment, using a modeling approach not previously applied in the evaluation of CCT programs, to the best of our knowledge. Because we do not have before-after measurements under a controlled environment required for the well-known "differences-in-differences" approach for program evaluation, we combine propensity scoring $[8,12,35]$ with a econometric model of consumer behavior to tease out the net impact of Bolsa Familia on consumption priorities among participating families, several years after the program was fully and nationally implemented. In other words, instead of using controlled experiments to test whether a CCT program might work before its implementation, the focus of our study is in estimating or assessing how the program is actually working after full implementation.

The main purpose of this study is to assess the impact of Bolsa Familia, the world's largest conditional cash transfer program currently in place. This CCT program today directly affects more than $20 \%$ of the Brazilian population and consequently is the subject of considerable political debate. Supporters of the program claim that it was responsible for the emergence of a new class of consumers in the first decade of the twenty-first century [23] and also contributed to the fast growth of the Brazilian economy during the same period. Among CCT programs implemented across the globe, Bolsa Familia is said to have produced the greatest multiplicative effect on the country's economy, with an additional $1 \%$ spent on the program resulting in a $1.8 \%$ increase in the entire country's economic activity [29]. Detractors argue that the program is creating a culture of dependency on handouts, and that substantial (relative to their current income) transfer of cash to extremely poor, uneducated families not accustomed to act as consumers in the marketplace leads them to squander the additional funds into superfluous impulse purchases [32, 40]. We use actual consumption data gathered in the latest national survey of consumer expenditures in Brazil (Pesquisa de Orçamentos Familiares, POF 2009 [31]) to objectively identify shifts in consumption among participants of Bolsa Familia, via a budget allocation model that allows us to identify two distinctive shifts: (a) a budget effect, which leads households to increase the consumption of non-essentials when they see an increase in their discretionary income and (b) a shift in consumption priorities, which would result in shifts in consumption regardless of the changes in discretionary income. We find that consumption patterns among participants of Bolsa Familia are distinct from comparable households, and there are indeed shifts in consumption priorities, rather than mere shifts due to budget effects. However, we find that these shifts in priorities occur mostly in essential consumption, rather than luxuries, contrary to what is typically claimed by detractors of the program.

Next, we present a brief summary of various conditional cash transfer programs and of their assessment in the literature. We then describe the framework for quasi-experiment design via propensity scoring, and the budget allocation model that we will later utilize to assess the impact of Bolsa Familia on the consumption behavior among its participants. This is followed by the presentation of our empirical work and discussion of its results and implications.

\section{Conditional Cash Transfer Programs}

The core of a CCT program is the cooperation and coresponsibility between family and government, each committing towards getting the family off its vulnerable state and improving its living conditions. CCT programs differ from traditional welfare programs because they require proof, on a periodic basis, that the family fulfilled the behavioral commitments made to receive the cash transfer, with the goal of producing a structural shift in the family's socioeconomic condition. Otherwise, families are warned and ultimately taken from the program. This co-responsibility between state and citizenry distinguish CCT programs from traditional welfare programs which typically do not require specific commitments from recipients [25]. CCT programs are grounded on two fundamental dimensions, to overcome abject poverty. On the short run, the direct transfer of cash attempts to alleviate immediate and urgent needs caused by poverty, such as hunger, health, and the disintegration of the family unit. On the long run, CCT programs attempt to disrupt the perpetuation of poverty over generations by inducing advances in the educational status of children and improvements in health and employability of its beneficiaries through the conditionalities. These conditionalities, in turn, potentially lead to social inclusion of the participating families and better job opportunities $[19,22,25,46]$. The general opinion regarding this form of welfare program is that "solid evidence of their positive impacts in reducing short-term poverty and increasing the use of education and health services" ([15], p. 27). Therefore, CCT programs may play an important role as instruments of income redistribution and economic development for emerging nations.

Since the pioneering CCT programs in Brazil (Bolsa Escola in 1995) and Mexico (Progresa in 1997), there has been a substantial number of new such programs implemented across more than 30 countries, including Argentina, Bangladesh, Bolivia, Brazil, Burkina Faso, Cambodia, Chile, 
Dominican Republic, Indonesia, Jamaica, Kenya, Mexico, Nicaragua, Nigeria, Panama, Pakistan, Paraguay, Peru, and Turkey. Such programs have seen considerable growth among developing nations, and even in developed ones such as the USA, which implemented its first CCT program in 2007 [5, $30,47]$. These programs have received substantial support from international development agencies, which identified CCT programs as one of the best practices for social protection for populations at a high state of socioeconomic vulnerability $[15,22]$.

The largest CCT program across the globe is Bolsa Familia, in Brazil, which has been mentioned as a main contributor for the $4.7 \%$ drop in Brazil's Gini coefficient and a $19 \%$ drop in extreme poverty in Brazil between 1996 and 2004 [45]. Bolsa Familia covers the largest population, benefiting 14 million families facing poverty or extreme poverty, directly transferring over US\$ 11 billion annually, with an overall impact that represents $0.5 \%$ of the country's GNP [29]. This program includes conditionalities in health and education. For health, families must commit to maintain a schedule of immunization and anthropometric tracking for children up to 7 years old; females 14 to 44 years old must take annual health checkups and, if pregnant or lactating, must follow a pre-natal care program and periodic checkups of both mother and baby. As for education, all children must show proof of minimum school attendance ( $85 \%$ for children between 6 and 15 years old, $75 \%$ for those at age 16-17); children up to 15 years old at risk of child labor must also participate in an after-school program with minimum attendance of $85 \%$ [28].

These CCT programs represent an important departure from traditional paternalistic welfare programs because they are based on the premise that the main causes of poverty are its perpetuation over generations and the lack of investments and accumulation of human capital $[18,44]$. CCT programs aim to change behavior within their target population so that, on the long run, these individuals will attain higher standards of living, particularly in terms of health, education, and employability $[27,33,43]$.

\section{The Assessment of Conditional Cash Transfer Programs}

Past research has shown how CCT programs changed some behaviors among the beneficiary families. The Opportunity program in New York attained a reduction of $33 \%$ in nutritional deficiency [30], along with improvements in primary school attendance and perceived well-being [42]. Rawlings and Rubio [34] show that, in Mexico, there was an increase in school attendance of $0.91 \%$ among boys and $1.21 \%$ among girls, from a baseline of $92 \%$, while in Nicaragua, there was an improvement of $22 \%$ in school attendance, compared to a baseline of $68.5 \%$ among children not benefitting from the CCT program. In Brazil, Lindert et al. [25] show that
$96.8 \%$ of Bolsa Familia participants met the school attendance conditionality of the program, compared to a baseline of $85 \%$ among those not benefiting from the program in the same period (from 2004 to 2006). Moreover, in these countries, there was also a substantial reduction in the number of children and adolescents absent from school due to child labor $[6,22]$.

In terms of health, Gertler [17] shows that in Mexico, there were an increase of $42 \%$ in visits to health centers among children under 2 years of age and a drop of $12 \%$ in the incidence of acute-care needs, due to the Progresa program. Hoddinott and Skoufias [20] also show a significant impact for Progresa in the growth rate of Mexican children. However, adult Mexicans benefiting from the same program showed higher rates of hypertension and obesity [14]. Rawlings and Rubio [34] point out that in Nicaragua, the general immunization rate among children up to 2 years old increased by $18.3 \%$ over a baseline of $63.6 \%$, while children up to 3 years old monitored by the program showed a growth rate $29.1 \%$ higher than a baseline of $62.7 \%$. In Brazil, $99.6 \%$ of the families receiving Bolsa Familia met the requirements related to health (immunization and anthropometric monitoring), while $85.4 \%$ of pregnant women received periodic pre-natal checkups [25].

In general, one can characterize previous assessments of CCT programs into two types. First, there are many tracking studies, based on independent samples, conducted during the implementation of the CCT program, to gauge improvements in health, housing, nutrition, and employment over time among participants [36]. Second, there are relatively fewer before-after experiments with a control group of non-participants, conducted before or at the early stages of implementation. In these experiments, the researcher selects two samples, one composed of regions or groups of households chosen to participate in the CCT program and another control sample of similar regions or households, who are held without the CCT benefit, as a control $[39,36]$.

In the first type of cross-sectional tracking study, the main potential problems are (a) typically, the samples utilized in each period are independent from previous ones, making it impossible to track longitudinal changes at the individual level, limiting the researcher to aggregate comparisons that confound longitudinal shifts with sampling errors; (b) sample sizes in each tracking survey tend to be small, reducing the statistical power of the longitudinal assessment of the CCT program [11]; (c) these tracking surveys are conducted for the specific purpose of assessing the CCT program, which is likely to bias the respondents' reporting [39]; and (d) data on behaviors beyond the conditionalities of the program, such as how the transferred funds were spent, are typically gathered in interviews, rather than in a detailed diary, leading to over (under)-reporting of socially (un)desirable consumption [21]. 
The main problems with the second type (experimental) of assessment for a CCT program are that (a) they tend to be conducted before the plan in fully implemented, when it is still possible to randomly allocate subjects to receive or not the cash transfers and to measure behaviors before participation in the program [1]; (b) random assignments to treatment and control are difficult to obtain in field experiments associated with a social program, because it is difficult to isolate participants from non-participants, which results into selection biases [39]; (c) the use of a "before" measurement in the typical before-after experiment results in an interactive testing bias whereby the prior measurement influences how the subject will respond to treatment [26]; (d) given that the treatment group receives a conditional cash transfer, it is likely that the dropout rate in this group will be lower than in the control group [4]; and (e) because of the potential communication between participants and non-participants in a social program, and because it would be unethical and politically infeasible to prevent qualifying families to join the CCT program, there will likely be migration of subjects from the control to the treatment group [39].

Overall, the main difficulty in assessing a CCT program after it has been implemented is that qualifying households self-select to participate in it. It would be politically untenable (and unethical) to prevent qualifying families from participating in the program only for the sake of experimentation, once it has been implemented. After all, these programs have great social and economic impact and have the potential to alter the lives of the most vulnerable members of society. Even if such a random assignment was possible, these social programs are public and highly publicized, therefore qualified families will likely learn about them from neighbors, family, and friends. Once the program has been implemented (as is the case here), the researcher loses the ability to manipulate treatments and outcome measurements in a controlled field experiment.

This is the main reason we propose a "natural" experiment based on data that was not gathered with the purpose of assessing the CCT program, in which reporting households were not primed in any way regarding the CCT program with any sort of prior measurement attempt, and data were gathered via consumption diaries with direct personal supervision. We rely on propensity scoring [35] to adjust the sample from a national consumer-expenditure survey, so that we obtain a comparable "control" group for an after-only quasi-experiment, thereby avoiding the problems identified above for the cross-sectional tracking studies and field experiments conducted in the past to assess CCT programs. We also rely on an econometric model to measure the impact of the program after accounting for other observed and unobservable differences between participants and non-participants. Crosssectional tracking studies and field experiments are useful methods for testing a CCT program prior to its implementation, or for tracking its progress during implementation. The methodology we describe and apply in this study is more appropriate to our case, where the focus is on assessing a CCT program after it has been implemented.

A common characteristic of the literature on the effect of conditional cash transfers is its focus on social impacts, in terms of health and education. However, as noted in the literature, CCT programs affect participants in ways that go well beyond the conditions imposed to the participants. The first impact relates to the role of CCT programs as a source of income for the participating families. Malucio and Flores [27] show that the RPS program in Nicaragua is responsible for $18 \%$ of the annual expenditures by the participating households. Skoufias [43] verified that Progresa in Mexico contributed to an increase of $20 \%$ in the consumption budget among participating households, relative to their budget prior to joining the program.

A second impact is the shift in consumption priorities. Rawlings and Rubio [34] found that the consumption budget among participants in the Progresa program increased by $13 \%$, while expenditures in food was $11 \%$ higher among participating households. These authors also found that the higher food expenditures were directed towards fruits, vegetables, legumes, and animal protein. According to Handa and Davis [18], the PRAF program in Honduras, RPS in Nicaragua, $F A$ in Colombia, and Progresa in Mexico produced a significant increment both in the purchase of food and in caloric consumption [27]. To the best of our knowledge, there is limited empirical evidence on how CCT programs affect consumption behavior beyond food consumption, despite the substantial discretionary income injected by such programs; Bolsa Familia, in Brazil, is credited for putting an extra R\$ 24 billion in the hands of its participants in 2013 [29]. Critics of Bolsa Familia claim that a considerable portion of this discretionary income given to households below the poverty rate is squandered in luxuries [10,40], although there is limited empirical evidence in the literature to support these critics. The natural experiment we conduct in our study attempts to document the shifts in consumption that can be attributed to Bolsa Familia as a conditional cash transfer.

\section{Designing a Natural Experiment from Cross-sectional Data with Propensity Scoring}

Our main purpose is to understand how conditional cash transfers affect the pattern of consumption among participating families. First, one would expect a "budget effect" because, as more cash is available to these low-income families, it is likely to be directed for consumption. Because these families were living at the subsistence level before joining the program, thereby not meeting their basic needs, one would expect the additional cash to be spent on basic necessities, rather than non-essentials, unless consumption priorities somehow shift 
because of the cash transfers. This shift in consumption priorities is one of the most common criticisms of cash handouts to the poor without any constraints on how it can be spent $[10$, $32,40]$, but only with conditions to receive the cash transfer. Supporters of CCT programs, on the other hand, argue that access to public services, more education, and social assistance induce more conscientious shifts in consumption priorities, leading to changes in consumption towards basic essentials.

In order to isolate the budget effect from shifts in consumption priorities associated with Bolsa Familia, we utilize data from a nationwide household expenditure survey (Pesquisa de Orçamentos Familiares-POF) conducted by the Brazilian Geo-Statistical Institute (IBGE) in 2009, after this CCT program had been already fully implemented. This expenditure survey included a detailed diary-based description of the household consumption budget across all categories of goods and services, as well as a complete socioeconomic and demographic profile of the household and its members. The survey also contained information about the household's participation in Bolsa Familia, including the amount of cash transferred during the year. Most importantly, the geographically and demographically stratified sample of 50,013 households is projectable to the population of 58 million households in Brazil during that period.

Instead of relying on a controlled "before-after" experiment on a small sample, we will compare the behavior of Bolsa Familia participants to non-participants based on a large-scale cross-sectional study of a nationally representative sample of households in 2009, from the Brazilian national survey of household budgets (or POF as it is known in Brazil). However, cash transfer programs are specifically targeted to low-income families with pregnant women, young children, or school-age children [45] following a selection rule unknown to the researcher at the household level. Moreover, households self-select into the program, because some of these disenfranchised families lack information about it, and might not be willing or able to meet its conditions. Therefore, one must take into account this unknown (self-) selection rule when comparing participants to non-participants. In other words, in order to identify a "control" group of comparable families not participating in Bolsa Familia, one must take into account the unobservable selection decisions made by the target population and policy makers. To define this comparable sample of non-participants of Bolsa Familia, we first select all non-participating households in the POF survey that fall in the same per capita income range as the net (before cash transfers) income range of participants, resulting into a sample of 30,647 non-participants and 9035 participants. We then use propensity scoring $[8,12,35]$ to weight each non-participant according to their likelihood of qualifying for the Bolsa Familia program with the goal of producing a weighted sample of non-participants that is equivalent in size and sociodemographic profile to the sample of participants to the Bolsa Familia program.

Propensity scoring is now commonly applied to estimate causal treatment effects from non-experimental data (see $[8$, 12] for a review). The main goal of propensity scoring is to balance two non-experimental groups on observed covariates so that a model estimated on the propensity-adjusted data can produce unbiased estimates of the effects of a treatment distinguishing the two groups. Propensity scoring is particularly useful when random assignment of subjects into treatment and control groups is not feasible, ethical, or politically justifiable, when subjects may self-select into the experimental cells. This is exactly the case here, in assessing the impact of Bolsa Familia after its full implementation, where qualified households decide, on their own, whether to participate in the program, and therefore, a before-after experimental design with randomly assigned treatment and control groups is not feasible.

The main disadvantage of natural experiments such as the one we designed is that the nonrandom selection of participants (treatment) and non-participants (control) may result in differences between the two groups that can be mistaken for treatment effects (selection bias). On the other hand, participants, treatments measurements, and overall settings in these natural experiments may reflect real-world conditions better than controlled, randomized experiments. Therefore, a crucial step in analyzing the results from quasi-experiments is the balancing of treatment and control groups to minimize potential selection biases [41]. Propensity scores are typically obtained by fitting a logistic regression explaining group (treatment/control) assignment as a function of subject characteristics that are believed to explain (self-) selection. Predicted group membership probabilities are then used as propensity scores for sample matching, stratification, covariance adjustment, or weighting each subject. A comprehensive discussion of the different approaches is beyond the scope of our application, and we therefore direct the reader to Shadish et al. [41] and Caliendo and Kopeinig [8] for more details and for testimonies on the validity of the results obtained from propensityscored quasi-experiments.

To obtain the sampling weights, we first estimate a binary logistic regression explaining program participation as a function of household demographics that potentially explain differences between participants and non-participants. We then use the predicted probability of program participation for each household in our sample, to define a control group that is comparable to the treatment group before receiving the benefits from the program. Table 1 presents the estimates for this logistic regression explaining participation in Bolsa Familia in 2009. In general, these results are not surprising; they indicate that the likelihood to participate in Bolsa Familia is lower for educated high-income households headed by single males (compared to single females), with children younger than 
Table 1 Propensity scoring model

\begin{tabular}{|c|c|c|c|c|c|}
\hline & & $B$ & Std. error & Sig. & $\operatorname{Exp}(B)$ \\
\hline & Intercept & -3.04 & 0.25 & 0.00 & 0.05 \\
\hline & PerCapitaBaseIncome & -0.41 & 0.01 & 0.00 & 1.00 \\
\hline \multirow[t]{4}{*}{ Urbanization } & Capital & -0.51 & 0.05 & 0.00 & 0.60 \\
\hline & Metro & -0.36 & 0.08 & 0.00 & 0.69 \\
\hline & SmallTown & -0.06 & 0.03 & 0.11 & 0.95 \\
\hline & Rural & 0 & & & \\
\hline \multirow[t]{7}{*}{ Age of the head of household } & $<25$ & 0.17 & 0.10 & 0.08 & 1.19 \\
\hline & $25-29$ & 0.65 & 0.09 & 0.00 & 1.91 \\
\hline & $30-39$ & 0.73 & 0.08 & 0.00 & 2.07 \\
\hline & $40-49$ & 0.73 & 0.08 & 0.00 & 2.08 \\
\hline & $50-59$ & 0.72 & 0.08 & 0.00 & 2.06 \\
\hline & $60-69$ & 0.35 & 0.08 & 0.00 & 1.42 \\
\hline & $70+$ & 0 & & & \\
\hline \multirow[t]{3}{*}{ Marital status } & Couple & -0.01 & 0.04 & 0.70 & 0.99 \\
\hline & Single male & -1.06 & 0.08 & 0.00 & 0.35 \\
\hline & Single female & 0 & & & \\
\hline \multirow[t]{5}{*}{ Number of kids } & kids0_4 & 0.04 & 0.03 & 0.16 & 1.04 \\
\hline & kids5_9 & 0.52 & 0.02 & 0.00 & 1.68 \\
\hline & kids10_14 & 0.57 & 0.02 & 0.00 & 1.77 \\
\hline & kids15_19 & 0.43 & 0.02 & 0.00 & 1.54 \\
\hline & North & 0.94 & 0.06 & 0.00 & 2.56 \\
\hline \multirow[t]{4}{*}{ Region } & Northeast & 1.28 & 0.05 & 0.00 & 3.61 \\
\hline & Southeast & 0.23 & 0.06 & 0.00 & 1.26 \\
\hline & South & -0.04 & 0.08 & 0.58 & 0.96 \\
\hline & Midwest & 0 & & & \\
\hline \multirow[t]{5}{*}{ Education } & Less than elementary & 1.53 & 0.23 & 0.00 & 4.63 \\
\hline & Elementary & 1.45 & 0.23 & 0.00 & 4.28 \\
\hline & Middle school & 1.17 & 0.23 & 0.00 & 3.23 \\
\hline & High school & 0.91 & 0.23 & 0.00 & 2.49 \\
\hline & College or more & 0 & & & \\
\hline
\end{tabular}

Values in Italics are statistically significant at the $p<0.05$ level

school age, living in metropolitan areas of the South, Midwest, and Southeast (the richest regions in Brazil). As one would expect, participation in Bolsa Familia is more likely for households headed by less-educated middle-aged adults with kids in school age, living in the rural areas or small towns of the North and Northeast (the poorest regions in Brazil). While the estimates of the logistic regression have general face validity, this is not our main purpose for the model, especially because these participation probabilities reflect both self-selection and qualification for the CCT program. We are more interested in the estimated Bolsa Familia participation probabilities assigned to each household, which we will use as the propensity weights to obtain a control group of nonparticipants with similar characteristics as the "treatment" (participant) group.

In order to ascertain that the sample of non-participants of Bolsa Familia is comparable to participants after the former are weighted by their propensity scores (thereby minimizing the potential for selection bias between our weighted control and treatment groups), we compare their demographic profiles in Table 2. With only two major exceptions (North and Northeast), the two samples are indistinguishable at the $p<0.01$ statistical significance level, despite the strong statistical power of the test (due to the large sample involved). The North has a lower share of participants $(18.3 \%)$ than non-participants $(20.3 \%)$, while the Northeast has a higher share of participants $(58.9 \%)$ than non-participants $(56.2 \%)$. While these differences are statistically significant at the $p<0.01$ level, they are relatively small in magnitude, reflecting similar profiles for both groups. Moreover, these differences reflect a widely discussed bias of Bolsa Familia in favor of the Northeast, the strongest political base for the government granting these cash transfers. For the other important variable (per 
Table 2 Comparison of matched samples on basic demographics

\begin{tabular}{|c|c|c|c|c|c|}
\hline Variable & Level & No $(\%)$ & Yes $(\%)$ & Total $(\%)$ & Significance \\
\hline \multirow[t]{4}{*}{ Urbanization } & Capital & 13.8 & 12.8 & 13.3 & 0.03 \\
\hline & Metro & 3.7 & 3.5 & 3.6 & 0.51 \\
\hline & SmallTown & 48.1 & 47.8 & 48.0 & 0.70 \\
\hline & Rural & & & & \\
\hline \multirow[t]{7}{*}{ Age of the head of household } & $<25$ & 3.7 & 3.5 & 3.6 & 0.59 \\
\hline & $25-29$ & 10.4 & 9.8 & 10.1 & 0.14 \\
\hline & $30-39$ & 32.5 & 32.3 & 32.4 & 0.73 \\
\hline & $40-49$ & 27.6 & 28.0 & 27.8 & 0.57 \\
\hline & $50-59$ & 15.6 & 16.2 & 15.9 & 0.28 \\
\hline & $60-69$ & 7.0 & 7.1 & 7.0 & 0.91 \\
\hline & $70+$ & & & & \\
\hline \multirow[t]{3}{*}{ Marital status } & Couple & 75.9 & 76.6 & 76.3 & 0.29 \\
\hline & Single male & 2.5 & 2.3 & 2.4 & 0.51 \\
\hline & Single female & & & & \\
\hline \multirow[t]{4}{*}{ Number of kids } & kids0_4 & 0.34 & 0.33 & 0.33 & 0.29 \\
\hline & kids5_9 & 0.58 & 0.59 & 0.58 & 0.65 \\
\hline & kids10_14 & 0.65 & 0.68 & 0.66 & 0.01 \\
\hline & kids15_19 & 0.47 & 0.47 & 0.47 & 0.90 \\
\hline \multirow[t]{5}{*}{ Region } & North & 20.3 & 18.3 & 19.3 & 0.00 \\
\hline & Northeast & 56.2 & 58.9 & 57.5 & 0.00 \\
\hline & Southeast & 12.2 & 12.0 & 12.1 & 0.54 \\
\hline & South & 4.1 & 4.1 & 4.1 & 0.95 \\
\hline & Midwest & & & & \\
\hline \multirow[t]{5}{*}{ Education } & Less than elementary & 47.7 & 49.5 & 48.6 & 0.01 \\
\hline & Elementary & 32.0 & 30.8 & 31.4 & 0.10 \\
\hline & Middle school & 10.2 & 9.8 & 10.0 & 0.35 \\
\hline & High school & 9.8 & 9.6 & 9.7 & 0.69 \\
\hline & College or more & & & & \\
\hline
\end{tabular}

capita income net of cash transfers), a more elaborate, model-based comparison was necessary because this variable depends on family composition. In other words, one should expect a household with many older kids to require a higher per capita income (and consumption budget) than another household with a single adult and no children to maintain the same standard of living. Therefore, to compare weighted non-participants and participants on net per capita income, we ran a linear regression explaining this variable as a function of household composition and participation in the Bolsa Familia program. We found that, after accounting or family composition, program participation had no statistically significant impact (at the $p<0.01$ level) on net (of cash transfers) per capita income, thereby leading to the conclusion that the control group is also comparable to Bolsa Familia participants on this important variable. Based on these and previously discussed comparisons, we conclude that propensity scoring produces a sample of nonparticipants that are directly comparable to participants of Bolsa Familia in 2009.

\section{Assessing the Impact of Bolsa Familia on Consumption with a Random-Effects Budget Allocation Model}

The propensity scoring described and tested above allows us to infer the impact of Bolsa Familia on the consumption behavior of its participants without relying on a controlled before-after controlled experiment, which is not feasible in the assessment of a program after it has been already fully implemented. However, propensity scoring only accounts for observable differences between "treatment" and "control" groups in our natural experiment. In order to also control for unobservable differences between the two groups, we need a model that measures the impact of program participation on behavior, while accounting for both observable and unobservable effects across participant and non-participant households. We want to compare the observed consumption of participants and equally qualified non-participants to understand how the additional discretionary income offered by the Bolsa Familia might have affected the behavior of its participants, after taking into account observed heterogeneity (via exogenous 
variables) and unobserved heterogeneity (via latent factors), along with error correlations across consumption categories and households (again, captured by latent factors).

Obviously, the cash transfer will produce an increase in the consumption budget, because participants are among the poorest families in the country, and therefore all discretionary income will be devoted to consumption. However, it is also possible that participation in the program may lead to unanticipated shifts in consumption priorities, leading to changes in the way the consumption budget is allocated across categories. For this comparison, we apply the budget allocation model of Du and Kamakura [13] to the reported expenditures by the 39,682 households selected from the POF sample, across the 21 categories defining their consumption budget. This budget allocation model offers many benefits for understanding how the consumption patterns of participants of Bolsa Familia differ from comparable non-participants. First, it takes into account the multivariate nature of the decision-making process, assuming that each household had to allocate its discretionary income across multiple competing consumption categories, to meet its needs throughout the year. Second, the model handles the unique characteristics of the observed allocations, with many categories receiving zero budget allocations that vary considerably across households and a clear budget constraint that also varies across households. Third, this budget allocation model allows us to isolate two important drivers of the observed allocations: (a) consumption priorities, which determine how a household prioritizes the allocation of the limited discretionary income across the various consumption categories to meet the needs of the household, and (b) a budget effect, which forces households with more limited discretionary incomes to focus their allocations towards essential consumption categories and allows wealthier households to "splurge" on non-essential consumption. Finally, and most importantly for our purposes, this budget allocation model allows us to explain the differences in consumption priorities across households, allowing us to isolate the impact of Bolsa Familia, from other household characteristics.

Following Du and Kamakura [13], we assume that household $i$ maximizes a direct utility function $G\left(q_{i}\right)$ over a set of $J$ non-negative quantities $q_{i}=\left(q_{1 i}, q_{2 i}\right.$, $\left.\ldots, q_{J i}\right)$ for all consumption categories, subject to a budget constraint $p^{\prime} q_{i} \leq m_{i}$, where $p=\left(p_{1}, p_{2}, \ldots p_{j}\right)^{\prime}>0$ contain the price for the competing consumption categories, and $m_{i}$ is household $i$ 's total (exogenous) consumption budget. Following Du and Kamakura [13], we use the Stone-Geary utility function, which has the following form:

$$
G\left(q_{i}\right)=\sum_{j=1}^{J} \alpha_{j i} \ln \left(q_{j i}-\beta_{j}\right)
$$

where $\alpha_{j i}>0$ is a household-specific "taste" parameter defining its consumption priorities for category $i$ and $\left(q_{j i}-\beta_{j}\right)>0$. This budget allocation problem implies that the household incrementally allocates its disposable income to the consumption category that produces the highest marginal utility per dollar, $\frac{\frac{\partial G\left(q_{i}\right)}{\partial q_{j i}}=\alpha_{j i}}{\left(q_{j i}-\beta_{j}\right)}$, given the current consumption levels $q_{i}$, until the budget limit is reached, or $\sum_{j=1}^{J} q_{j i}=m_{i}$. Notice that, contrary to Du and Kamakura [13], we specify the budget allocation model directly on the value spent on each consumption category, thereby ignoring prices. We do this because we are analyzing consumption on only 1 year, and therefore prices do not vary within each category. The only possibility to consider prices would have been to consider regional prices for each consumption category and each household, which unfortunately were not available to us. Therefore, the estimates obtained from the budget allocation model should be interpreted as preferences or priorities for expenditures, rather than quantity consumed in each category.

Instead of allowing only for unobserved heterogeneity (i.e., diversity in underlying preferences not accounted by the observed predictors) in the taste parameter $\left(\alpha_{j i}\right)$ for each category $i$, as in Du and Kamakura [13], we also explain the households' consumption priorities using descriptors of the households' composition and their treatment/control status, captured by the predictor vector $\left(W_{i}\right)$

$\alpha_{j i}=\exp \left(\gamma_{j}+\delta_{j} W_{i}+\lambda_{j} Z_{i}+\varepsilon_{j i}\right)$

where

- $\gamma_{j}=$ intercept for consumption category $j$.

- $\quad Z_{i}=k$-dimensional factor scores for household $i$ that capture unobserved heterogeneity in consumption priorities across households.

- $\quad \lambda_{j}=k$-dimensional factor loadings for category $j$, which capture correlations among consumption categories due to unobserved differences in consumption priorities across households.

- $W_{i}=$ vector of exogenous characteristics of household $i$, to account for demographic effects, (including treatment/ control status) on consumption priorities. The following demographic characteristics, available in the POF database, are considered:

- CCT - 1 if the household participated in Bolsa Familia, 0 otherwise

- Capital - 1 if the household lives in a state capital

- Metro - if it lives in a metropolitan area

- Smalltown - if it lives in a small city

- Residents — number of household members 
- age25-1 if the head of household is 25 years old or younger

- age29-1 if the head of household is between 26 and 29 years old

- age39-1 if the head of household is between 30 and 39 years old

- age49-1 if the head of household is between 40 and 49 years old

- age59-1 if the head of household is between 50 and 59 years old

- age69-1 if the head of household is between 60 and 69 years old

- couple - 1 if the head of household is married

- singmale - 1 if the head of household is a single, divorced or separated male

- white - 1 if the head of household is White

- black - 1 if the head of household is Black

- asian - 1 if the head of household is Asian

- mulato-1 if the head of household is Mulato

- kids0 4 number of children under 5 years old

- kids5_9- number of children between 5 and 9 years old

- kids10_14 number of children between 10 and 14 years old

- kids 15-19-number of children between 15 and 19 years old

- kids20_24 - number of children between 20 and 24 years old

- bedrooms - number of bedrooms in residence

- bathrooms - number of bathrooms in residence

- citywater - 1 if the residence is connected to a city water network

- pavement -1 if the residence is in a paved street

- percapinc - per capita monthly household income

- $\delta_{j}=$ vector of regression coefficients.

- $\varepsilon_{j i}=$ random error (assumed as independently identically distributed, because correlations across categories and households are captured by the latent factor structure $\left(\lambda_{j} Z_{i}\right)$.

Calibration of the model on this sample, weighted by the projection weights (to project the sample to the population of households in Brazil in 2009) and propensity lead to the measures of fit shown in Table 3. For each consumption category, Table 3 reports two measures of fit. The first one (hit-rate) measures the ability of the model in identifying buyers and non-buyers of the category. In this regard, the budget allocation model performs more poorly in categories with lower incidence across households, such as travel, jewelry and accessories, and health insurance than in categories that are consumed across most households, such as food at home and utilities. The second measure of fit shows the percentage of variance explained by the model for expenditures
Table 3 Fit statistics for the estimated budget allocation model

\begin{tabular}{lcl}
\hline Category & Hit rate (\%) & Explained variance (\%) \\
\hline Food and beverage at home & 91.2 & 74.8 \\
Food and beverage away & 60.3 & 36.9 \\
Utilities & 97.0 & 48.0 \\
Home maintenance & 30.2 & 13.9 \\
Cleaning products & 37.4 & 57.7 \\
Home furnishings & 64.5 & 32.9 \\
Communications & 54.2 & 33.7 \\
Public transport & 42.1 & 44.7 \\
Car maintenance & 36.1 & 40.4 \\
Travel & 29.2 & 19.5 \\
Apparel & 85.5 & 62.3 \\
Jewelry and accessories & 31.2 & 27.1 \\
Hygiene and personal & 70.7 & 42.9 \\
Health & 81.9 & 23.6 \\
Health insurance & 43.0 & 18.7 \\
Education & 54.5 & 20.9 \\
Recreation and culture & 52.9 & 38.4 \\
Professional services & 46.8 & 17.9 \\
Personal services & 78.1 & 21.3 \\
Other expenses & 65.5 & 31.4 \\
Housing & 100.0 & 90.7 \\
\hline
\end{tabular}

observed among households consuming the category. Considering that these measures of fit were computed across a very large sample of close to 40,000 households across 20 consumption categories on highly truncated data and that the data are error-prone annualized estimates from weekly and monthly reported expenses, we characterize the fit of the budget allocation model as adequate.

Parameter estimates from the budget allocation model are reported in Table 4. Estimates for the CCT dummy predictor in Table 4 clearly show that participants in the Bolsa Familia have different revealed preferences for the competing consumption categories than those not participating in the program, after accounting for other observed and unobservable differences. From these estimates, one can see that CCT has a positive coefficient for all consumption categories, implying that CCT recipients have a lower priority for housing (defined as the benchmark in the budget allocation model) than nonrecipients relative to all other consumption options. This might be due to the fact that housing consumption cannot be as easily adjusted on the short/medium term as other types of consumption (e.g., food, personal care), and therefore CCT recipients are less prone to allocate their extra consumption budget to it. Another potential explanation for this lower revealed priority for housing is the bias of Bolsa Familia towards household in the Northeast, discussed earlier; housing costs are lower in that region than in most of the country, and 
馬

च 黄

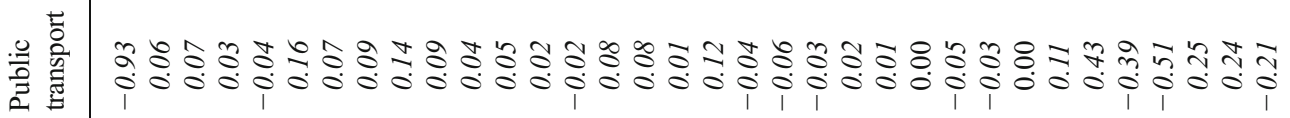

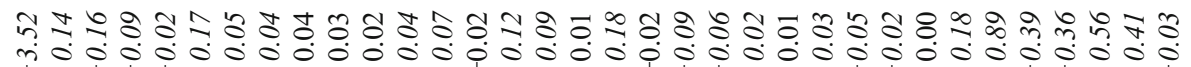

局

.00
$\frac{.00}{5}$
0
0
0

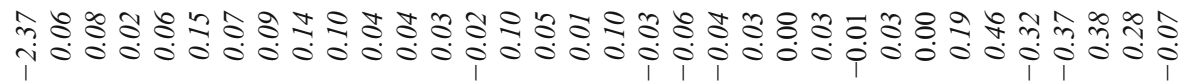

曾

रำ

is

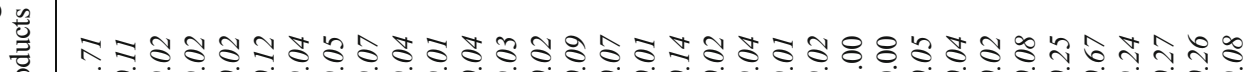

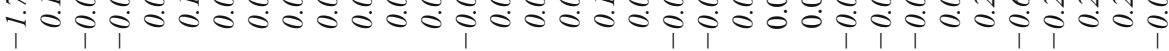

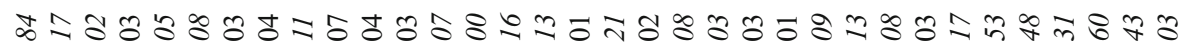

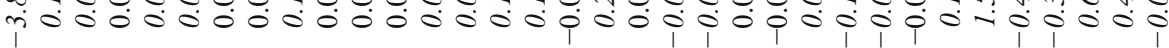

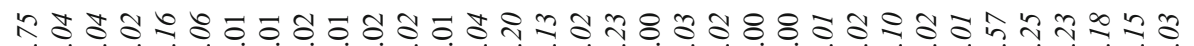

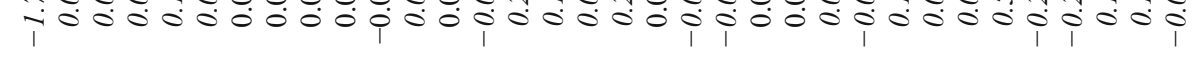

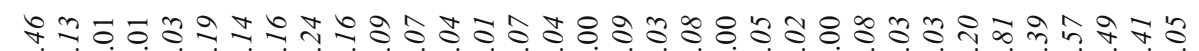
i.

응 


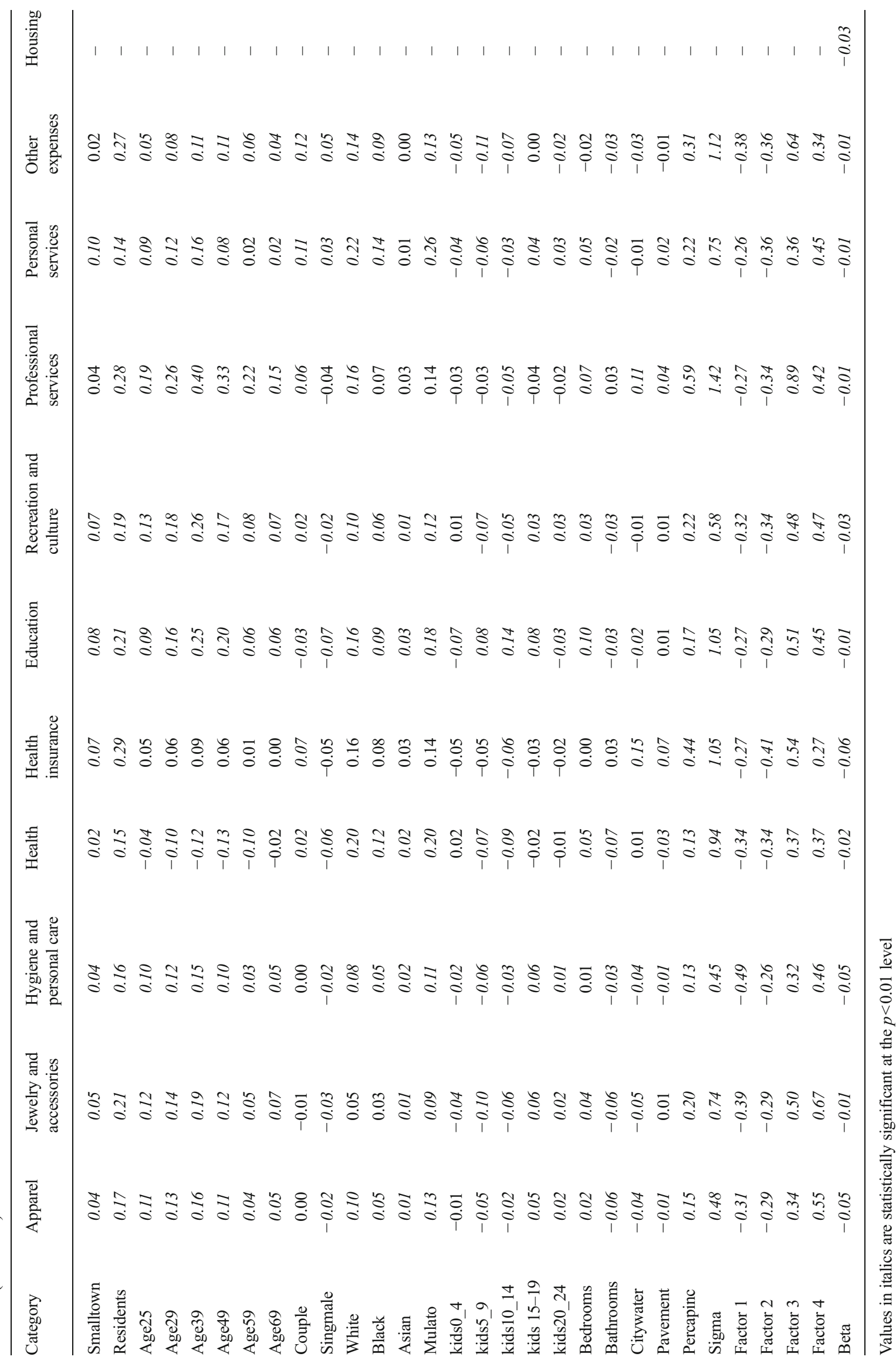


since expenses are not adjusted by regional price differences, these lower costs would appear as a lower revealed preference or priority for housing.

In general, the estimates in Table 4 cannot be directly interpreted, because they represent the effect of the CCT predictor in each of 20 competing consumption categories, and therefore they must be interpreted in the same way one would interpret the estimates from a multinomial Logit model, relative to a baseline category (housing). For this reason, we use the algorithm shown in Kamakura and Du [24] to produce counterfactual simulations that show more directly how consumption patterns among participants in the Bolsa Familia might have changed due to the CCT program. We use this algorithm to simulate how participants of Bolsa Familia (weighted by the sampling projection factors, in order to project the POF 2009 sample to the Brazilian population of households in 2009) distributed their consumption budget under three different scenarios:

1. No cash transfer-This is the baseline scenario, simulating consumption without any cash transfer from Bolsa Familia, given the parameter estimates in Table 3, and individual household scores $Z_{i}$.

2. Cash transfer, no priority shift-In this scenario, we exclude the impact of the CCT program on priority shifts; this scenario, compared to the baseline one, allows us to isolate budget effects due to Bolsa Familia.

3. Cash transfer, priority shift-This scenario allows us to measure the full impact of the Bolsa Familia program on the consumption behavior of participating households, when compared to the baseline scenario.

The results from the three policy simulations described above are displayed in Table 5, projected for the population of Brazilian households at the time of the POF survey (2009). According to these projections, about 7.5 million households (about $13 \%$ of a projected population of 59 million households in 2009 based on our sample) benefited from the Bolsa Familia. The results on Table 5 may be interpreted as those from a post-test or after-only quasi-experiment [26] with the control group defined by propensity scoring. Therefore, the estimated effects represent differences between households who participated in Bolsa Familia during 2009 and families with comparable (pre-CCT) profiles who did not participate in the program. Based on our sample of 9035 participant families, we estimate that Bolsa Familia resulted in an injection of R \$ 7.5 billion in discretionary income, representing an increment of $10 \%$ in buying power for participant families. Our results clearly indicate that participants of Bolsa Familia assign lower consumption priority to housing, public transport, and utilities than comparable non-participants. This lower priority could be due to the bias of Bolsa Familia towards households in the Northeast (as shown in Table 2 and discussed earlier), where the cost of living, and particularly the cost of housing, is lower than that in the South, Southeast, and Midwest.

Contrary to what critics of the program claim, our empirical results indicate that this discretionary income was not squandered into superfluous consumption. According to our results, $47 \%$ of the incremental budget was spent on food and beverages (at home and away from it), with an additional $9 \%$ spent on apparel. Other categories with substantial share of the incremental budget include cleaning products $(5.8 \%)$ and health (5.4\%), suggesting a focus towards covering basic essentials, rather than splurging on superfluous consumption. Two of the most non-essential categories (communications and recreation and culture) received less than $5 \%$ of the extra budget.

Most importantly, the impact of Bolsa Familia on consumption created substantial new demand for basic, essential goods. Focusing on the essential categories with the largest share of incremental consumption (food and beverages, apparel, cleaning products, and health), the Bolsa Familia program represented an additional $\mathrm{R} \$ 4.4$ billion in demand for basic goods, or an increase of $13 \%$ in the demand for these goods in 2009 among participant households. This incremental demand for essential goods becomes more substantial when one takes into account that participants of Bolsa Familia are highly concentrated in the North and Northeast regions; based on the entire sample of POF 2009, we estimate that the North and Northeast account for over $78 \%$ of all Bolsa Familia participating households, compared to only $33 \%$ of the population of households in the country.

\section{Conclusions and Discussion}

The main challenge we faced in this study was the assessment of a social program after it had been fully implemented. The distinction between testing a social program before and assessing its impact after full implementation is more than merely semantic. Testing whether a new social program will work provides the researcher the freedom to randomly allocate subjects to treatment and control groups, and to measure outcomes before and after the subjects' exposure to the program, leading to the well-known "before-after with control" experimental design [26]. Even in these controlled preimplementation tests, one must deal with threats to internal validity, such as migration of subjects from one treatment to another, dropouts, etc. because, in a field study, the experimenter does not have full control over exposure to the treatment. Assessing whether a social program is working after full implementation, on the other hand, limits the ability of the researcher to manipulate exposure to the program and to measure outcomes before the program's implementation. That is 
Table 5 Estimated expenditure shares from counterfactual analyses

\begin{tabular}{|c|c|c|c|c|c|c|c|c|}
\hline & \multirow[t]{2}{*}{ Households } & \multicolumn{3}{|l|}{ Cash transfer } & \multicolumn{4}{|c|}{ Estimated effects } \\
\hline & & $\begin{array}{l}\text { No cash transfer } \\
\text { (millions) }\end{array}$ & $\begin{array}{l}\text { No priority shift } \\
\text { (millions) }\end{array}$ & $\begin{array}{l}\text { Shift } \\
\text { (millions) }\end{array}$ & $\begin{array}{l}\text { Budget effect } \\
\text { (millions) }\end{array}$ & $\begin{array}{l}\text { Priority shifts } \\
\text { (millions) }\end{array}$ & $\begin{array}{l}\text { Both effects } \\
\text { (millions) }\end{array}$ & $\begin{array}{l}\text { Share of } \\
\text { gains (\%) }\end{array}$ \\
\hline FoodBevIn & $7,439,827$ & $\mathrm{R} \$ 24,303$ & $\mathrm{R} \$ 26,858$ & $\mathrm{R} \$ 27,119$ & $\mathrm{R} \$ 2555$ & $\mathrm{R} \$ 261$ & $\mathrm{R} \$ 2815$ & 37.5 \\
\hline FoodBevOut & $7,439,827$ & $\mathrm{R} \$ 3475$ & $\mathrm{R} \$ 3794$ & $\mathrm{R} \$ 4180$ & $\mathrm{R} \$ 319$ & $\mathrm{R} \$ 387$ & $\mathrm{R} \$ 705$ & 9.4 \\
\hline Utilities & $7,439,827$ & $\mathrm{R} \$ 4801$ & $\mathrm{R} \$ 5270$ & $\mathrm{R} \$ 4874$ & $\mathrm{R} \$ 469$ & $\mathrm{R} \$ 396$ & $\mathrm{R} \$ 73$ & 1.0 \\
\hline HomeMaintenance & $7,439,827$ & $\mathrm{R} \$ 837$ & $\mathrm{R} \$ 923$ & $\mathrm{R} \$ 1125$ & $\mathrm{R} \$ 86$ & $\mathrm{R} \$ 201$ & $\mathrm{R} \$ 288$ & 3.8 \\
\hline CleaningProds & $7,439,827$ & $\mathrm{R} \$ 2613$ & $\mathrm{R} \$ 2898$ & $\mathrm{R} \$ 3046$ & $\mathrm{R} \$ 285$ & $\mathrm{R} \$ 148$ & $\mathrm{R} \$ 433$ & 5.8 \\
\hline HomeFurnishings & $7,439,827$ & $\mathrm{R} \$ 1714$ & $\mathrm{R} \$ 1875$ & $\mathrm{R} \$ 2069$ & $\mathrm{R} \$ 160$ & $\mathrm{R} \$ 194$ & $\mathrm{R} \$ 355$ & 4.7 \\
\hline Communications & $7,439,827$ & $\mathrm{R} \$ 3070$ & $\mathrm{R} \$ 3364$ & $\mathrm{R} \$ 3211$ & $\mathrm{R} \$ 294$ & $\mathrm{R} \$ 153$ & $\mathrm{R} \$ 141$ & 1.9 \\
\hline PublicTransport & $7,439,827$ & $\mathrm{R} \$ 7275$ & $\mathrm{R} \$ 8050$ & $\mathrm{R} \$ 7573$ & $\mathrm{R} \$ 775$ & $\mathrm{R} \$ 477$ & $\mathrm{R} \$ 298$ & 4.0 \\
\hline CarMaintenance & $7,439,827$ & $\mathrm{R} \$ 1847$ & $\mathrm{R} \$ 2013$ & $\mathrm{R} \$ 2235$ & $\mathrm{R} \$ 165$ & $\mathrm{R} \$ 222$ & $\mathrm{R} \$ 387$ & 5.2 \\
\hline Travel & $7,439,827$ & $\mathrm{R} \$ 838$ & $\mathrm{R} \$ 921$ & $\mathrm{R} \$ 1042$ & $\mathrm{R} \$ 83$ & $\mathrm{R} \$ 121$ & $\mathrm{R} \$ 204$ & 2.7 \\
\hline Apparel & $7,439,827$ & $\mathrm{R} \$ 4754$ & $\mathrm{R} \$ 5210$ & $\mathrm{R} \$ 5455$ & $\mathrm{R} \$ 456$ & $\mathrm{R} \$ 245$ & $\mathrm{R} \$ 701$ & 9.3 \\
\hline JewelryAccessories & $7,439,827$ & $\mathrm{R} \$ 245$ & $\mathrm{R} \$ 266$ & $\mathrm{R} \$ 297$ & $\mathrm{R} \$ 22$ & $\mathrm{R} \$ 31$ & $\mathrm{R} \$ 53$ & 0.7 \\
\hline HygieneCare & $7,439,827$ & $\mathrm{R} \$ 3293$ & $\mathrm{R} \$ 3613$ & $\mathrm{R} \$ 3668$ & $\mathrm{R} \$ 320$ & $\mathrm{R} \$ 55$ & $\mathrm{R} \$ 375$ & 5.0 \\
\hline Health & $7,439,827$ & $\mathrm{R} \$ 2695$ & $\mathrm{R} \$ 2940$ & $\mathrm{R} \$ 3100$ & $\mathrm{R} \$ 245$ & $\mathrm{R} \$ 160$ & $\mathrm{R} \$ 405$ & 5.4 \\
\hline HealthInsurance & $7,439,827$ & $\mathrm{R} \$ 299$ & $\mathrm{R} \$ 324$ & $\mathrm{R} \$ 261$ & $\mathrm{R} \$ 25$ & $-\mathrm{R} \$ 63$ & $-\mathrm{R} \$ 38$ & -0.5 \\
\hline Education & $7,439,827$ & $\mathrm{R} \$ 637$ & $\mathrm{R} \$ 696$ & $\mathrm{R} \$ 891$ & $\mathrm{R} \$ 59$ & $\mathrm{R} \$ 194$ & $\mathrm{R} \$ 253$ & 3.4 \\
\hline RecreationCult & $7,439,827$ & $\mathrm{R} \$ 1337$ & $\mathrm{R} \$ 1459$ & $\mathrm{R} \$ 1533$ & $\mathrm{R} \$ 122$ & $\mathrm{R} \$ 75$ & R\$ 197 & 2.6 \\
\hline ProfServices & $7,439,827$ & $\mathrm{R} \$ 130$ & $\mathrm{R} \$ 139$ & $\mathrm{R} \$ 149$ & $\mathrm{R} \$ 9$ & $\mathrm{R} \$ 10$ & $\mathrm{R} \$ 19$ & 0.3 \\
\hline PersonalServ & $7,439,827$ & $\mathrm{R} \$ 689$ & $\mathrm{R} \$ 747$ & $\mathrm{R} \$ 721$ & $\mathrm{R} \$ 58$ & $-\mathrm{R} \$ 27$ & $\mathrm{R} \$ 31$ & 0.4 \\
\hline OtherExpenses & $7,439,827$ & $\mathrm{R} \$ 1353$ & $\mathrm{R} \$ 1462$ & $\mathrm{R} \$ 1602$ & $\mathrm{R} \$ 109$ & $\mathrm{R} \$ 140$ & $\mathrm{R} \$ 249$ & 3.3 \\
\hline Housing & $7,439,827$ & $\mathrm{R} \$ 8079$ & $\mathrm{R} \$ 8969$ & $\mathrm{R} \$ 7640$ & $\mathrm{R} \$ 890$ & $\mathrm{R} \$ 1329$ & $-\mathrm{R} \$ 439$ & -5.8 \\
\hline TotalBudget & $7,439,827$ & $\mathrm{R} \$ 74,284$ & $\mathrm{R} \$ 81,791$ & $\mathrm{R} \$ 81,791$ & $\mathrm{R} \$ 7507$ & $\mathrm{R} \$ 0$ & $\mathrm{R} \$ 7507$ & 100.0 \\
\hline
\end{tabular}

precisely the challenge we faced in this study, which we attempted to circumvent by combining two approaches.

First, because we did not have control over who received the conditional cash transfers, we relied on propensity scoring to define a sample of households who did not participate in the Bolsa Familia program, but was comparable to the sample of participants, after the proper propensity weighting. With propensity scoring, we managed to define a comparable weighted sample of non-participants of the CCT program and build an after-only quasi-experiment.

Second, in order to analyze the data from this quasiexperiment and tease out different effects of the cash transfers on consumption behavior, we applied a budget allocation model where participation in Bolsa Familia was one of many predictors explaining the observed allocation of the consumption budget across 20 categories. This model was necessary because we wanted to ensure that observable (and unobservable) differences between participants and non-participants were still accounted for, when assessing the impact of the CCT program, and because we wanted to tease out two effects of the CCT program on consumption: the budget effect, by which consumers tend to spend more on non-essentials when facing any sort of windfall (when the normal budget already covered essential consumption), and true shifts in consumption priorities. Accounting for unobservable differences in consumption priorities is particularly important because propensity scoring only accounts for observable factors that lead households to participate (or not) in a welfare program.

Based on this hybrid approach, we found that 7.5 million households directly benefitted from Bolsa Familia in 2009, representing close to $13 \%$ of the population of households in the country. Because the poorest households in Brazil tend to have a larger number of members, the reach of Bolsa Familia in 2009 was even greater when measured in number of benefitted individuals. In 2013, the program served 13.8 million households, representing about a quarter of the Brazilian population [9].

We estimate that the CCT program resulted into R $\$ 7.5$ billion in additional discretionary income injected into the economy in 2009, mostly in the North and Northeast of Brazil, which accounted for $78 \%$ of participants in the program. Despite of the claim by critics of this welfare program that participants squander their easily earned extra cash on superfluous consumption, we found that essential consumption absorbed the majority (more than $65 \%$ ) of the additional discretionary income. 
In our policy simulations, we assumed that all the cash transferred to participants of the program would be devoted to consumption. We made this assumption because only households below the poverty level qualified for this program, and therefore, these households had no access to credit to pay back, and had no means to divert the extra income towards savings or investments.

The analyses and conclusions reported in our study only refer to the direct impact of Bolsa Familia on the consumption behavior of participant households. It is highly likely that the injection of R $\$ 7.5$ million in areas populated by the most poor households in the country would have had a multiplicative effect [29], because of the generally high concentration of poverty in the North-Northeast and in the periphery of large urban centers [38]. At a national level, experts estimate that an extra $1 \%$ spent on Bolsa Familia would result in an increase of $1.8 \%$ in the country's GDP [29].

Our study is also limited to the impact of the CCT program on consumption on a single year. It is likely that the extra demand for essential goods created in the poverty pockets of the country will result in inflation without the necessary investments in infrastructure and production capacity, along with improvements in productivity to increase supply. It is also possible that the exposure to extra discretionary income over extended periods may result in some form of dependence on the long run, unless extra measures are taken to increase human capital among participants. We leave the study of these important long-term effects of Bolsa Familia for future research.

\section{References}

1. Angelucci M, Attanasio O (2009) Oportunidades: program effects on consumption, low participation and methodological issues. Econ Dev Cult Chang 57(3):479-506

2. Attanasio OP, Costas M, Santiago A (2011) Education choices in Mexico: using a structural model and a randomized experiment to evaluate PROGRESA. Rev Econ Stud 79:37-66

3. Avila P (2012) On the evaluation of conditional cash transfer programs: an analysis of CCT programs and poverty. Thesis. Columbia University, New York

4. Baird S, McIntosh C, Ozler B (2010) Cash or condition? Evidence from a cash transfer experiment. Working Paper n. 5259, World Bank, Washington (DC)

5. Bastagli F (2011) Conditional cash transfers as a tool of social policy. Econ Polit Wkly XLVI(21), May

6. Bourguignon F, Ferreira FHG, Leite PG (2003) Conditional cash transfers, schooling, and child labor: micro-simulating Brazil's Bolsa Escola Program. World Bank Econ Rev 17(2):229-254

7. de la Brière B, Rawlings LB (2006) Examining conditional cash transfer programs: a role for increased social inclusion? Discussion Paper n.0603, World Bank Institute, Washington (DC)
8. Caliendo M, Kopeinig S (2008) Some practical guidance for the implementation of propensity score matching. J Econ Surv 22(1): 31-72

9. Campello T, Neri MC (2013) Programa Bolsa Família: uma década de inclusão e cidadania. Ipea, Brasília

10. Cotta RMM, Machado JC (2013) Programa Bolsa Familia e seguranca alimentar e nutricional no Brasil: revisão critica da literatura. Rev Panam Salud Publica 33(1):54-60

11. Cunha LS, Motta AP (2011) Programa Bolsa Familia: Repercussoes nas condicoes de vida dos beneficiarios no sertao de Canudos. In: Anais do I Circuito de Debates Academicos. Ipea, Rio de Janeiro (RJ)

12. Dehejia RH, Wahba S (2002) Propensity score matching methods for non-experimental causal studies. Rev Econ Stat 84(1):151-161

13. Du RY, Kamakura WA (2008) Where did all that money go? Understanding how consumers allocate their consumption budget. J Mark 72(6):109-131

14. Fernald LCH, Gertler PJ, Hou X (2008) Cash component of conditional cash transfer program is associated with higher body mass index and blood pressure in adults. J Nutr 138:2250-2257

15. Fiszbein A, Schady N, Ferreira F, Grosh M, Kelleher N, Olinto P, Skoufias E (2009) Conditional cash transfers: reducing present and future poverty. The World Bank, Washington

16. Gaarder MM (2010) Experimental and quase-experimental designs. International Initiative for Impact Evaluation. Available at http:// www.3ieimpact.org. Accessed August 8, 2014

17. Gertler PJ (2000) The impact of Progresa on health. Final Report, International Food Policy Research Institute, Washington (DC)

18. Handa S, Davis B (2006) The experience of conditional cash transfers in Latin America and the Caribbean. Dev Pol Rev 24(5):513-536

19. Heinrich CJ (2007) Demand and supply-side determinants of conditional cash transfer program effectiveness. World Dev 35(1):121-143

20. Hoddinott J, Skoufias E (2004) The impact of PROGRESA on food consumption. Econ Dev Cult Chang 53(1):37-61

21. Ibase (2008) Repercussoes do programa bolsa familia na seguranca alimentar e nutricional das familias beneficiadas. In: Relatorio Tecnico. Ibase, Rio de Janeiro (RJ)

22. Kakwani N, Soares F, Son HH (2005) Conditional cash transfers in African Countries. In: Working Paper n.9, International Poverty Centre. PNUD, Brasilia (DF)

23. Kamakura WA, Mazzon JA (2013) Socioeconomic status and consumption in an emerging economy. Int J Res Mark 30:4-18

24. Kamakura WA, Du RY (2012) How economic contractions and expansions affect expenditure patterns. J Consum Res 39(2):229-247

25. Lindert K, Linder A, Hobbs J, de la Brière B (2007) The nuts and bolts of Brazil's Bolsa Familia Program: implementing conditional cash transfers in a decentralized context. Discussion Paper n.0709, World Bank Institute, Washington (DC)

26. Malhotra NK (2010) Marketing research: an applied orientation, 6th edn. Prentice Hall, Boston

27. Malucio JA, Flores R (2005) Impact evaluation of a conditional cash transfer program: the Nicaraguan red de Protección Social. Research Report n.141. International Food Policy Research Institute, Washington (DC)

28. MDS (2011) SIGPBF-Sistema de Gestao do Programa Bolsa Familia. Available at http://aplicacoes.mds.gov.br. Acessed 4 June 2011

29. Neri MC, Vaz FM, Souza PHGF (2013) Efeitos macroeconomicos do programa Bolsa Familia: uma analise comparativa das transferencias sociais. In: Campelo T, Neri MC (Org) (eds) Programa Bolsa Familia: uma decada de inclusao e cidadania. Ipea, Brasilia (DF)

30. NPC (2010) Sharing lessons from the first conditional cash transfer program in the United States. Policy Brief 22, September

31. POF 2009 (2010) Pesquisa de Orçamentos Familiares 2008-2009: Aquisição alimentar domiciliar per capita Brasil e Grandes Regiões. Rio de Janeiro, Instituto Brasileiro de Geografia e Estatistica 
32. Queiroz ECAA (2011) Programa Bolsa Familia: criticas e perspectivas. In: Monografia. Universidade Estadual da Paraiba, Campina Grande (PB)

33. Rawlings LB (2005) A new approach to social assistance: Latin America's experience with conditional cash transfer programmes. Int Soc Secur Rev 58(2):133-161

34. Rawlings LB, Rubio GM (2005) Evaluating the impact of conditional cash transfer programs. World Bank Res Obs 20(1):29-55, Spring

35. Rosenbaum PR, Rubin DB (1984) Reducing bias in observational studies using subclassification on the propensity score. J Am Stat Soc 79:516-524

36. Saavedra JE, Garcia S (2012) Impacts of conditional cash transfer programs on educational outcomes in developing countries: a metaanalysis. Working Paper n. 921-1, Rand, Santa Monica (CA)

37. Samson M, van Niekerk I, Mac Quene K (2010) In: Huston K, Schwartz C (eds) Designing and implementing social transfer programmes: a policy manual. South Africa

38. Schawarsman S (2009) Bolsa Familia: mitos e realidades. Interesse $\mathrm{Nac} 2(7): 20-28$

39. Seads (2008) Avaliacao de impacto do efeito conjugado de programas de transferencia de renda e complementares na regiao metropolitana de Sao Paulo. In: Relatorio Tecnico. Secretaria Estadual de Assistencia e Desenvolvimento Social, Sao Paulo (SP)

40. Seixas AP (2009) Grife isso: Eu uso marcas de luxo! Uma analise do consumo de produtos de grife por individuos de classes populares.
Dissertacao, Universidade Federal de Minas Gerais, Belo Horizonte (MG)

41. Shadish WR, Luellem JK, Clark MH (2006) Propensity scores and quasi-experiments: a testimony to the practical side of Lee Sechrest. In: Bootzin RR, McKnight PE (eds) Strenghtening research methodology and evaluation. American Psychological Association, Washington, pp 143-157

42. Silva MMS (2008) Opportunity NYC: a performance-based conditional cash transfer programme. A qualitative analysis. Working Paper n.49, International Poverty Centre. PNUD, Brasilia (DF)

43. Skoufias E (2005) PROGRESA and its impacts on the welfare of rural households in Mexico. Research Report n.139, International Food Policy Research Institute, Washington (DC)

44. Skoufias E, McClafferty B (2001) Is PROGRESA working? Summary of the results of an evaluation by IFPRI. Discussion Paper n.118, International Food Policy Research Institute, Washington (DC).

45. Soares FV, Soares SS, Sousa MM, Zepeda EM (2006) Cash transfer programmes in Brazil: impacts on inequality and poverty. Working Paper n.21, International Poverty Centre. PNUD, Brasilia (DF)

46. Weissheimer MA (2006) Bolsa Familia: Avancos, limites e possibilidades do Programa que esta transformando a vida de milhoes de familias no Brasil. Editora Fundacao Perseu Abramo, Sao Paulo

47. World Bank (2011) Conditional cash transfers key facts. Available at http://go.worldbank.org/bwuc1cmxm0. Accessed 3 June 2011 